\title{
Sentidos da educação cidadã no Brasil
}

\section{Meaning of the citizen education in Brazil}

\author{
Raquel Alvarenga Sena Venera*
}

\begin{abstract}
RESUMO
Esse trabalho versa sobre o sentido da educação cidadã, assumido nos documentos oficiais e entre os educadores, desde os eventos que permearam a abertura política no Brasil. Através de uma breve arqueologia/genealogia se propõe destacar a intimidade entre o Estado e a ciência pedagógica. Em diferentes tempos e espaços históricos, com personagens e contextos diversos, a cidadania, ou o ato dos sujeitos se posicionarem no social, tem sido objetivo a ser atingido no espaço escolar. Seja no Brasil do início do século XX, com os profissionais da Escola Nova, ou, no final do mesmo século com a evocação do nome Darcy Ribeiro para a construção da LDB, os sentidos da educação cidadã perpassam a utopia de Comenius ou a crença pedagógica de Rousseau.

Palavras-chave: Educação, cidadania; Estado.
\end{abstract}

\begin{abstract}
This work is about the meaning of the citizen education that educators have been assuming on official documents since the events that were around while the Brazilian political openning. Using a short archeology/ genealogy, the purpose is to show the intimacy between the State and pedagogical science. In different times and historical spaces, with many characters and contexts, citizenship has been an objective to be achieved in a school space. In Brazil, at the beggining of the $20^{\text {th }}$ century, with New School professionals, or in the end of the same century, with the evocation of the name of Darcy Ribeiro for the construction of LDB, the meaning of citizen education go beyond the Comenius' utopia or even the pedagogical belief of Rousseau.

Keywords: Education; citizenship; State.

* Mestre em História Cultural (UFSC), doutora em Educação (Unicamp), professora do Curso de História da Universidade do Vale do Itajaí, SC - Univali. E-mail: raquelsenavenera@
\end{abstract} hotmail.com 


\section{Delimitando a investigação}

Os discursos educacionais democráticos que emergiram no Brasil, no movimento da abertura política, foram sendo cristalizados especialmente no decorrer da década de 1990, com início ainda no final dos anos 80, com a Constituição de 1988, perpassando as indicações internacionais pós Declaração de Jomtien, em 1990, nas Leis de Diretrizes e Bases da Educação Nacional, em 1996, e nos Parâmetros Curriculares Nacionais, em 1998. Foram esses documentos que regularam os sentidos dos discursos de liberdade, autonomia, participação de todos, postura crítica, e que orientam a construção do cidadão. Discursos que emergiram como bandeiras da educação a partir da abertura política no Brasil e se transformaram em direitos e deveres.

Os discursos educacionais ligados à cidadania não nasceram naquele momento histórico. De onde podem ter vindo essas bandeiras que foram transformadas em palavras de ordem nas greves de professores, nos documentos oficiais, nas políticas públicas educacionais e na própria LDB? Que memória arquivo os professores brasileiros acessam para falar em liberdade, igualdade, criticidade e cidadania? Esse arquivo, ao qual se pretende identificar, é, como para Foucault (2000, p. 95), "o jogo das regras que, em uma cultura, determinam o aparecimento e o desaparecimento de enunciados, sua permanência e seu apagamento, sua existência paradoxal de acontecimentos e de coisas". Que sentidos foram regulados no conceito de cidadania, nos discursos educacionais brasileiros? Que sentido de educação escolar foi resignificado? Quais as relações dessa educação com a construção de um Estado democrático? Se o conceito de cidadania pode ser mapeado em outros espaços e tempos históricos, que outros sentidos ele representou?

\section{A formação do sentido de cidadania por meio do método arqueo- lógico e genealógico}

Uma arqueologia do conceito de cidadania permite perceber suas regularidades discursivas em um determinado extrato social, definido neste estudo entre a década de 1990 e o início do século XXI no Brasil. Construir um problema a partir de uma arqueologia permite investigá-lo a partir de sítios em escavação. Como, em momentos históricos e espaços diferentes, o conceito de cidadania a serviço da pátria e da promoção do bem comum é acionado? 
O extrato social privilegiado nesse texto - a contemporaneidade educacional brasileira - não pode ser analisado como efeito de ideias produzidas em outros sítios, outras camadas de pesquisa. Ele possui a sua própria história. No entanto, a história, aqui, está sendo entendida como um processo e, se os documentos educacionais são os discursos - abordados como a materialização dos sentidos produzidos no contexto social, no e pelos sujeitos -, os registros passados não estão desconectados do presente. Esses sentidos são produzidos ao longo da História e são incessantemente móveis, sendo resignificados, reconstruídos, negados, relidos e transformados. Uma genealogia desses conceitos é possível a partir da arqueologia.

Nessa direção seria desnecessário investigar a história dos conceitos que sinalizam mudanças democráticas no ensino brasileiro com o objetivo de buscar o sentido primeiro das palavras, ou ainda, o nascimento delas. Desta forma, estaríamos negando a polifonia da linguagem e fixando significantes aos significados. A tarefa da genealogia "não é a de mostrar que o passado ainda está lá, bem vivo no presente, animando-o ainda em segredo [...]" (FOUCAULT, 1999, p. 21). Vale ressaltar, então, o sentido de genealogia como emergência. Algo que se produz no interstício de um jogo de poder. A relação entre arqueologia e genealogia se faz, conforme o autor, "enquanto a arqueologia é o método próprio à análise da discursividade local, a genealogia é a tática que, a partir da discursividade local assim descrita, ativa os saberes libertos que emergem dessa discursividade" (FOUCAULT, 1999, p. 172).

A arqueologia e a genealogia dos discursos educacionais, produzidos na segunda abertura política brasileira, delimitam um problema contemporâneo - a cidadania a serviço da constituição do Estado democrático brasileiro. Além de dar visibilidade a outros sítios arqueológicos, sendo que o sentido contemporâneo de cidadania carrega ecos de sentidos de outros períodos históricos, nos quais os sentidos dos discursos educacionais e sua relação com o Estado são evocados, negados, re-significados e reinventados.

\section{Construindo e regulando sentidos de cidadania no contexto brasi- leiro}

A primeira materialidade dos sentidos para a educação brasileira contemporânea foi exposta na Lei de Diretrizes e Bases da Educação (LDB), promulgada em 1996. Esse documento evoca o nome de um educador que marcou a luta pelo direito educacional no Brasil - professor Darcy Ribeiro. Em meio às 
tensões políticas durante a elaboração desse documento, surge uma proposta, apresentada no Senado em nome do professor. O estado de saúde que marcava o final da vida do professor Darcy Ribeiro e o impossibilitava, em grande medida, para o trabalho intenso de elaboração de uma proposta de lei. Talvez houvesse aqui um empréstimo de seu nome para legitimar mais uma versão nas tensões políticas. Seu nome aciona vários sentidos que legitimam a própria lei.

A morte do professor Darcy Ribeiro, dias depois de assinar a proposta de lei, marcou o final da última geração da Escola Nova no Brasil. As ideias que permearam essa escola, desde o início do século XX, e a evocação de sua História em 1996, justificam a arqueologia aqui proposta - a busca, em outros extratos sociais, do tratamento desse sentido de libertação do homem, pela educação. Foi a partir da Escola Nova que surgiu o primeiro grupo de especialistas que pensou a racionalidade educacional no Brasil, desvinculada de dogmas religiosos. Esse grupo discursou sobre a educação como sendo o caminho necessário e urgente para ser pensada a construção da, na época, ainda jovem República. A educação passou a ser o caminho de emancipação do Estado.

A produção historiográfica da educação brasileira evidencia um Estado, no início do século XX, despossuído de um sistema educacional e de um conjunto de subjetividades que desejassem a educação com o sentido de direito para todos. Antes da Escola Nova, qual era a equipe brasileira de especialistas educacionais, além dos padres? A república brasileira nasceu sem um corpo de especialistas para pensar a educação de seus cidadãos. Anísio Teixeira, Fernando de Azevedo, Monteiro Lobato, entre outros, foram os chamados, anos mais tardes, de pioneiros da educação brasileira. A trajetória dos pioneiros, com todas as ressalvas e críticas a eles atribuídas, construiu para o grupo essa legitimidade de falar sobre a educação brasileira. O nome do professor Darcy Ribeiro fazia acionar, em 1996, a memória da História de conquistas da Educação brasileira. A esse grupo foi atribuído, no território pedagógico, sinônimos como expertice educacional, propagadores da igualdade de acesso à escola, promotores de civilidade e da ordem etc. Suas propostas não nasceram somente da necessidade que se fazia presente. Ao contrário, a necessidade foi detectada porque eles estavam imersos em discursos que os sensibilizaram para ver o Brasil daquela maneira e não de outra forma.

Estudos da realidade norte-americana, francesa, inglesa marcavam os pontos de apoio desse grupo. As cartas que esses educadores trocavam entre si revelam que eles se construíram numa verdadeira "irmandade pró-cidadania". Em 1929, quando Anísio Teixeira ainda estava na Bahia, Fernando de Azevedo lhe escreveu uma carta o convidando para estar onde a educação estava sendo pensada em um país de despreparados, e como sua presença poderia significar conquistas para o grupo e fortalecimento dessa irmandade. Ele diz: 
Você desculpe essa tirada, de que você não tem necessidade. (a crítica da República de homens despreparados) Mas é ela uma confirmação de "nossas hipóteses". Convém ser assinalada. É também um dos percalços da irmandade, de que você fala, repetindo o Lobato. O que é preciso é que a irmandade se desenvolva e não se ponha "a margem, fazendo obra de Jeremias..." Você tem assim obrigação de ação e necessidade de fazer combativo. Venha para o sul e a transformação de dará (LOURENÇO FILHO, 1929).

O que eles projetavam para o país dizia muito sobre o que experimentavam e liam sobre a educação em outras nações. Lourenço Filho escreveu, em 1961, uma obra intitulada "Educação Comparada", em que ele expõe 10 modelos educacionais de 10 países diferentes. No primeiro capítulo da obra, ele fala dos governos como "[...] Áustria e da Polônia criaram comissões especiais para exame do assunto" e as atenções eram para a criação de uma educação para todos. "Entre os anos de 1800 e 1850, a Suécia, a Noruega, a França, a Grécia, o Egito, a Hungria, a Dinamarca e a Áustria estabeleciam Ministérios de Instrução Pública" (LOURENÇO FILHO, 1961, p. 17). No caso especial da Polônia, verificamos que, um século antes, a obra "Didática Magna" estava sendo escrita por Jan Amos Comenius, muito embora não fosse posta em prática naquele país. Um século depois da publicação da obra pedagógica, Jean-Jacques Rousseau escreveu "Considerações sobre o Governo da Polônia e sua reforma projetada", onde expõe a educação num sentido muito próximo de Comenius.

No mesmo tempo que viveu Galileu Galilei - um personagem pensava a educação como caminho libertador do homem. Komensky, mais conhecido como Jan Amos Comenius, em meio às tensões político-religiosas da Guerra dos Trinta Anos, que envolveram toda a região da Boêmia, foi condenado ao exílio perpétuo na Polônia. Foi lá que elaborou suas ideias educacionais pautadas nos direitos iguais a todos os cidadãos, e, talvez, influenciado pelo contexto histórico que vivia, chamou suas ideias de "visão utópica". Mariano Narodowski (2001, p. 25) estudou a proposta comeniana e, segundo ele: "a utopia é a capacidade estruturante com a qual o pensamento pedagógico conta para construir seus próprios sujeitos". Seria própria da ciência pedagógica essa projeção, esse sonho constante de um sujeito que ainda não existe.

Pautado nessa utopia, Comenios elaborou uma série de livros que sinalizaram a educação sueca, e anos mais tarde, direcionou as ideias humanistas da educação no Parlamento inglês do século XVII. Para ele, "“todos têm de saber tudo'; é assim que os educadores devem 'ensinar tudo a todos"' (COMENIOS, 1997, p. 26), de tal forma que todas as classes deveriam receber uma única educação. Com essa proposta, ele levantou a hipótese de que, através da educação 
unificada e racional, se conquistaria uma ordem em toda a natureza, incluindo a humanidade do homem que conduziria a disciplina de suas vontades. Em sua obra mais conhecida - "Didática Magna" - ele diz: "ser criatura racional é ser observador, denominador e classificador de todas as coisas isso significa conhecer e poder nomear e entender tudo aquilo que o mundo inteiro encerra" (COMENIOS, 1997. p. 9). A educação moderna foi sinalizada como promotora da razão, da libertação do homem. Algo que o institui da capacidade e legitimidade de ser cidadão, de participar ativamente, obedecendo às regras do seu mundo. Ele acreditava que esse modelo de educação seria capaz de produzir uma envergadura de unidade no Estado.

As escolas deveriam atingir cada família, cada infância, em um projeto homogeneizador e, com esse programa geral de universalização do ensino, a utopia comeniana atingiria seu ponto máximo: a unidade. A compreensão errada da realidade levaria à desunião, à falta de harmonia social e política.

Comenius pensou a educação em um tempo em que a Instituição Escolar estava em construção. A subjetividade de pais que priorizam a educação dos filhos desde a infância, e a delega ao Estado, ainda estava em construção. Como falar de cidadania, de liberdade pela razão no século XVII, sem abarcar o sentido de utopia, vivendo em um mundo em que as crianças eram sequestradas pelo Estado para serem internadas nas escolas? ${ }^{1}$ Nos séculos XVII e XVIII, ainda era parca a popularidade da educação estatal, ainda era entendida pela grande maioria como um dever. Para essa resistência transformar-se em luta por um direito, muitas histórias foram vividas. Comenius se sentiu mais atraído pelos convites recebidos do Parlamento Inglês e do governo da Suécia e, não foi na Polônia o local de realização do modelo de suas escolas.

Um século depois, como se por um efeito profético comeniano, a Polônia se encontrava, exatamente, com um grande problema em suas estruturas internas, definido, na época, como "anarquia". Um problema que Comenius poderia nomear de desequilíbrio social. Três potencias disputavam o domínio da Polônia - a Prússia, a Rússia e a Áustria -, montando um cenário fragmentado para o governo. Nesse cenário, outro pensador, Jean-Jacques Rousseau, foi procurado por Wielhorski, um relações públicas daqueles que organizavam uma revolta contra o rei polonês apoiado pela Rússia. Era preciso planejar um caminho para, após a tomada do poder, fazer acontecer uma Polônia governável, livre da situação de "anarquia".

Nessa obra, que se configura quase como uma aplicação de sua obra anterior, "Contrato Social", em um caso específico, o autor, semelhantemente a Comenius, destaca a educação como caminho para produzir o sentimento de 
unidade do Estado. Ele diz: "Por que meios, pois, comover os corações e fazer amar as pátrias e as leis? Ousaria eu dizê-lo? Por meio de jogos de crianças; por meio de instituições ociosas aos olhos dos homens superficiais, mas que formam hábitos queridos e afeições invencíveis" (ROUSSEAU, 1982, p. 26).

O pensador abriu um subtítulo intitulado "Educação" para expor melhor sua tese. Ele sugere que a educação deve promover a forma nacional, direcionar os gostos de tal maneira que os cidadãos sintam a necessidade de serem patriotas (ROUSSEAU, 1982, p. 36).

Além dos investimentos necessários nas instituições escolares, ele formulou, também, ações educacionais externas à escola e direcionadas a todos os cidadãos. A comemoração, divulgação e celebração de fatos da história polonesa precisavam ser cuidadosamente escolhidas, privilegiando àqueles que fizessem silenciar os feitos russos.

\begin{abstract}
Não gostaria contudo que se permitissem nessas solenidades qualquer invectiva contra os russos, nem mesmo que se falasse deles. Seria honrálos demais. Esse silêncio, a lembrança de suas barbáries e o elogio dos que resistiram a eles, dirão deles tudo o que é preciso dizer: deveis desprezá-los demais para ainda por cima odiá-los (ROUSSEAU, 1982, p. 31-32).
\end{abstract}

Existe nessas celebrações uma educação dos gostos e dos desejos.

Voltando ao sítio brasileiro, porém, em outro tempo histórico, o grupo da Escola Nova, que nasceu como oposição à situação de governo a que foi instituída a república, passou a fazer parte nos primeiros anos de governo de Getúlio Vargas. Em resposta ao convite de Francisco Campos, Anísio escreveu a Lourenço Filho dizendo: "estou disposto a aceitar" e refere-se a "grandes coisas a iniciar". As "grandes coisas" era o projeto de construção de um Sistema Nacional de Educação que sinalizou as políticas de governo getulistas - especialmente a Nacionalização do Ensino frente às escolas dos imigrantes estrangeiros. Nas palavras de Getúlio ([-20?], p. 305): "aqui todos são brasileiros, porque nasceram no Brasil, porque no Brasil receberam educação". Observam-se vestígios do mesmo sentido de educação, aquele capaz de produzir uma unidade nacional. Não é novidade para os brasileiros que, no modelo educacional dessa época, os desfiles cívicos, semelhantes aos que Rousseau propôs - a comemoração, divulgação e celebração de fatos da história brasileira cuidadosamente escolhidas, privilegiando àqueles que fizessem silenciar as múltiplas histórias e que construísse um sentido de unidade da nação -, eram sempre presentes na prática pedagógica. 
Getúlio Vargas pronunciava em seus discursos sobre a educação um sentido nacionalista que privilegiava a educação dos homens para o trabalho e esse levava a nação ao sucesso econômico e cultural. Os sentidos da cidadania para esse chefe de Estado estavam conectados à moral, à ordem e ao progresso. Sobre as políticas militares, ele diz em 1938, algo que se confunde com o discurso educacional: "o programa de realização do Estado Novo compreende o reajustamento completo dos quadros da vida brasileira, desde a subestrutura econômica até à formação intelectual e moral das gerações novas" (VARGAS, [-20?], p. 249) e termina o discurso dizendo "só assim realizaremos o objetivo supremo de crescer organicamente, dentro dos limites territoriais, tendo, ao mesmo tempo, garantidos pelas nossas próprias forças, o trabalho produtivo, a circulação das riquezas, a paz e a prosperidade coletivas" (VARGAS, [-20?], p. 249). Com certeza não havia no Brasil outro nome mais indicado para assumir pastas no Ministério da Educação e Saúde do que os personagens da Escola Nova.

Em outra geração da Escola Nova, a ideia de educação para todos, propagada em meio às tensões com a igreja, encenava a atuação cada vez maior do setor privado. Esse fato foi concretizado em uma emenda constitucional de 1961. Antes disso a Escola Nova evidentemente já vinha se posicionando contrária e foi Fernando de Azevedo que vem outra vez a público, em 1959, com um segundo manifesto intitulado Manifesto dos Educadores. Mais uma vez convocados. A impressa foi palco de debates inflamados e lá estava Darcy Ribeiro com posturas irônicas provocando Clemente Mariani, então Ministro da Educação e o jornalista Carlos Lacerda. Darcy se projeta e fala em nome dos ideais dos pioneiros. Ele ficou conhecido como a figura que uniu a cultura popular, a pedagogia do oprimido ao se posicionar em defesa incondicional da escola pública de direito.

\section{Considerações finais}

O sentido que Comenius e Rousseau construíram para a educação a colocou definitivamente conectada aos interesses e demandas do Estado. E isso é perceptível na contemporaneidade. Por exemplo, hoje, o Estado brasileiro, diante da demanda que a violência expõe, precisa "sacar" da educação um modelo, uma ideia, uma forma de fazer, que amenize, que dilua, que administre, o problema, que inclua o grupo ameaçador. Quando os educadores brasileiros levantam a bandeira da educação cidadã acreditam que esse é um caminho para construir 
uma nação que seja uma república, um lugar para o bem comum. Utópico ou não, esse sentido vem se manifestando há séculos.

Delimitar o problema de análise dos discursos educacionais construídos na década de 1990 no Brasil, a partir da exposição de várias camadas sociais e de vários tratamentos que foram sendo moldados sobre os mesmos conceitos, permite o mapeamento de várias repetições que marcaram a diferença nos deslizamentos de sentidos. A partir disso permite também desenhar possíveis relações entre esses sentidos clareando o desenho de uma "episteme" dos discursos educacionais contemporâneos no Brasil.

Pensar no sentido de educação deixado nos textos de Comenius, de Rousseau, dos pioneiros da Escola Nova, nas intenções getulistas, revela que, apesar de se tratar de "sítios" diferentes, e dizerem sobre contextos históricos diferentes, a nós implicam no mapeamento de possibilidades, muito bem formuladas, que unem cada vez mais compromissadamente o Estado e a educação escolar. Importa ao nosso tempo a percepção de que o modelo democrático de Estado - escolhido por nós a partir da chamada abertura política - precisa da escola como dispositivo para a construção de subjetividades cidadãs.

\section{REFERÊNCIAS}

ARIÈS, Philippe. História Social da Criança e da Família. 2. ed. Tradução de: Dora Flaksman. Rio de Janeiro: LTC, 1981.

CARTAS de Anísio Teixeira. Acervo do Arquivo Anísio Teixeira CPDOC/FGV.

COMENIUS. Didática Magna. São Paulo: Martins Fontes, 1997.

FINKELSTEIN, Bárbara. Incorporando as crianças à História da Educação. Revista Teoria \& Educação, Porto Alegre, n. 6, 1992.

FOUCAULT, Michel. A Arqueologia do Saber. Rio de Janeiro: Forence Universitária, 1997.

. Microfisica do Poder. Rio de Janeiro: Graal, 1999.

. Sobre a Arqueologia das Ciências. Resposta ao Círculo da epistemologia. In: MOTTA, Manoel Barros da (Org.). Arqueologia das Ciências e História dos Sistemas de Pensamento. Rio de Janeiro: Forense Universitária, 2000. (Ditos e Escritos). 
GÉLIS, Jacques. A individuação da criança. In: CHARTIER, Roger (Org.). História da Vida Privada 3: da Renascença ao Século das Luzes. São Paulo: Cia das Letras, 1991.

LOURENÇO FILHO, M. B. Educação Comparada. São Paulo: Melhoramentos, 1961.

NARODOWSKI, Mariano. Comenius e a Educação. Belo Horizonte: Autentica, 2001.

REVISTA da Associação Nacional de Educação, ano 1, n. 5, 1982.

ROUSSEAU, Jean-Jacques. Considerações sobre o governo da Polônia e sua reforma projetada. São Paulo: Brasiliense, 1982.

VARGAS, Getúlio. As Diretrizes da Nova política do Brasil. Rio de Janeiro: José Olimpio, [-20?]. 